\title{
COMPARISON OF FLOW ANALYSIS OF A SUDDEN AND GRADUAL CHANGE OF PIPE DIAMETER USING FLUENT SOFTWARE
}

\author{
G.Satish $^{1}$, K.Ashok Kumar ${ }^{2}$, V.Vara Prasad ${ }^{3}$, Sk.M.Pasha ${ }^{4}$ \\ ${ }^{1,2,3,4}$ Assistant Professor, Department of Mechanical Engineering, Shri Vishnu Engineering College for Women, \\ Andhra Pradesh, India. \\ satishg@svecw.edu.in,ashokkumark@svecw.edu.in,veenamvaraprasad@gmail.com,pasha@svecw.edu.in
}

\begin{abstract}
This paper describes an analytical approach to describe the areas where Pipes (used for flow of fluids) are mostly susceptible to damage and tries to visualize the flow behaviour in various geometric conditions of a pipe. Fluent software was used to plot the characteristics of the flow and gambit software was used to design the $2 D$ model. Two phase Computational fluid dynamics calculations, using $K$-epsilon model were employed. This simulation gives the values of pressure and velocity contours at various sections of the pipe in which water as a media. A comparison was made with the sudden and gradual change of pipe diameter (i.e., expansion and contraction of the pipe). The numerical results were validated against experimental data from the literature and were found to be in good agreement.
\end{abstract}

Index Terms: gambit, fluent software.

\section{INTRODUCTION}

Pipes are the important media for transporting fluids (liquid or gases) from one place to another under pressure. The efficiency depends on minimize the losses in fluid flow is important. Pipes consist of elbows, T-junctions, bends, contractions, expansions and many other components. When a fluid flows through a pipe due to friction between walls and to the layers of fluids, the energy is converted into thermal energy. Hence energy losses are developed in terms of the fluid height known as the head losses. These losses are classified into major losses or linear head present throughout the length of the pipe and minor losses or singular head occurring due to minor appurtenance and accessories present in a pipe network.

These appurtenances encountered by the fluid flow are sudden or gradual changes of the boundaries resulting in a change in magnitude, direction or distribution of the velocity of the flow.

In case of sudden contraction, the flow separation in the vicinity of the contraction plane causes an increase in pressure loss, which affects erosion rates and heat and mass transfer rates at the separation and reattachment regions. The variation in pressure is due to Contraction of the flow to the vena contracta and expansion to the wall of the small pipe.

In case of sudden enlargement the area of the pipe increases suddenly along the length of the pipe (at a 90 degree angle). The downstream velocity will be lower than the upstream velocity. The energy lost is because of turbulence. Amount of turbulence depends on the differences in pipe diameters. Time to time many researchers worked in order to achieve a general and precise formulation of the diverse type of head losses. Weisbach, 1855 was the first one to give the concept of relation for head loss. Darcy and Weisbach formulated equation - Darcy - Weisbach formula to measure accurate pipe friction loss. It is one of the most accurate formulas for measuring the pipe friction loss but is difficult to calculate and use than the other friction formulas.

In this paper the analysis was done on very small area and common components of pipe network i.e. sudden contraction and sudden enlargement of pipes. The main aim behind the project is to find the solution to minimize head losses.

\section{DETAILED PROCEDURE}

The current study used FLUENT, to solve the balance equation using control volume approach. These equations are solved by converting the complex partial differential equations into simple algebraic equations.

Two dimensional geometry was used to study the flow in pipe for solving the mass, momentum, and energy equations. The phase velocities were defined at the inlet boundary of the pipe upstream. The к- $\varepsilon$ turbulence models with standard wall functions were used to solve the problems. The gravitational acceleration of $9.81 \mathrm{~m} / \mathrm{s} 2$ in upward flow direction was used. 


\section{GEOMETRY DETAILS}

The geometry was done in the GAMBIT with measurements, larger pipe diameter and length as $40 \mathrm{~mm}$ and $40 \mathrm{~mm}$, smaller pipe diameter and length as $20 \mathrm{~mm}$ and $60 \mathrm{~mm}$ in case of sudden contraction and enlargement. Similarly in case of gradual expansion and contraction of the pipe. Defining required boundaries like inlet, outlet and wall of the geometry and mesh under tetrahedron. The figure shows the mesh geometry of the fluid flow.

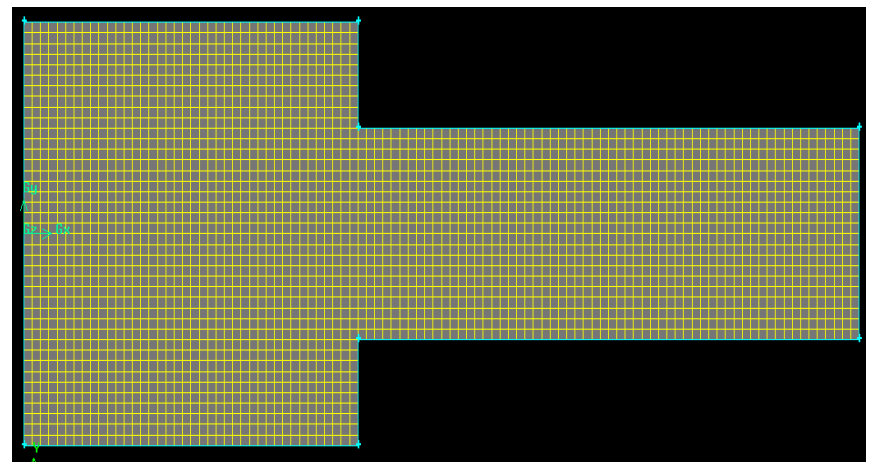

Fig-3.1: mesh geometry of sudden contraction.

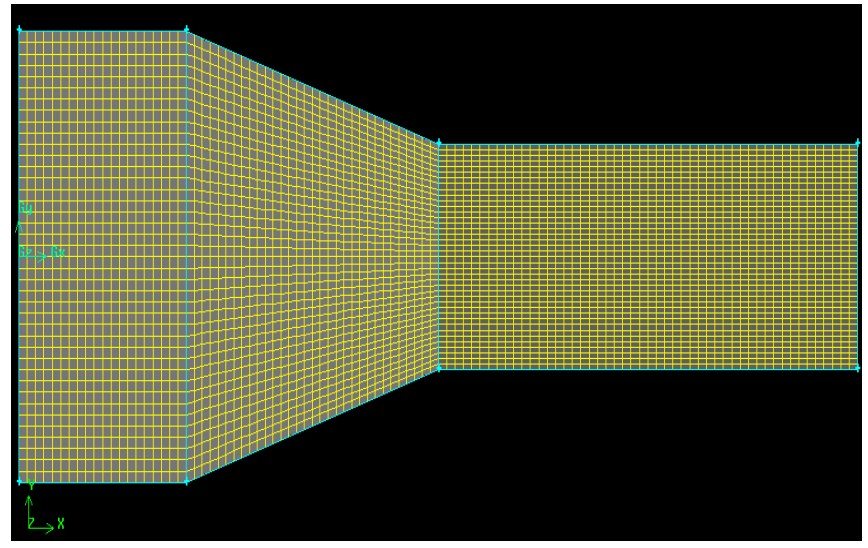

Fig- 3.2: mesh geometry of gradual contraction.

\section{SOLUTION STRATEGY \& CONVERGENCE}

The simulation is done in the FLUENT based upon the governing equations. The steps followed in the fluent are define Model, define Material, define cell zone, boundary condition, solve, iterate, and analyze results. The governing equations used to solve this problem as below.

\subsection{Continuity Equation}

Continuity Equation also called conservation of mass. Consider fluid moves from point 1 to point 2 .

The overall mass balance is Input - output $=$ accumulation Assuming that there is no storage the Mass input = mass output.

However, as long as the flow is steady (time-invariant), within this tube, since, mass cannot be created or destroyed then the above equation.

According to continuity equation, the amount of fluid entering in certain volume leaves that volume or remains there and according to momentum equation tells about the balance of the momentum. The momentum equations are sometimes also referred as Navier-Stokes (NS) equation. They are most commonly used mathematical equations to describe flow. The simulation is done based on the NS equations and then K-Epsilon model.

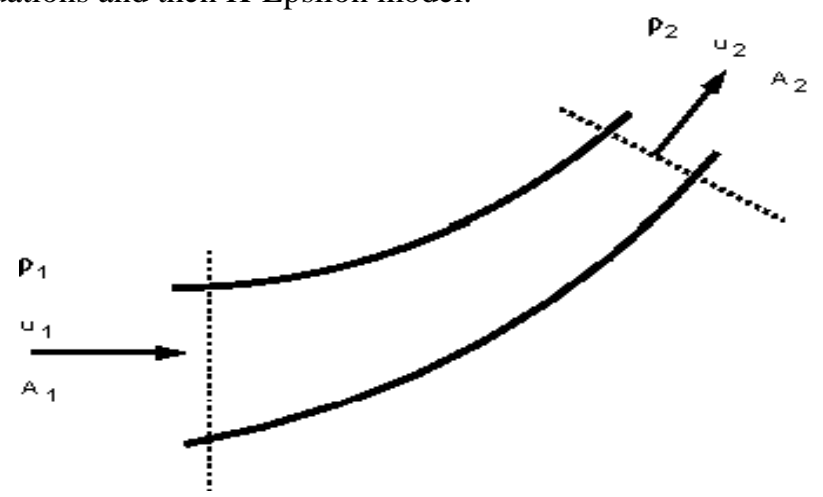

Fig-4.1: continuity equation

$$
\begin{gathered}
m_{1}=m_{1}^{\prime \prime} \\
\frac{d m_{1}}{d t}=\frac{d m_{1}}{d t} \\
\rho A_{1} u_{1}=\rho A_{2} u_{2} \\
A_{1} v_{1}=A_{2} v_{2}
\end{gathered}
$$

\subsection{Momentum Equation and Bernoulli}

\section{Equation}

It is also called equation of motion .According to Newton's 2nd law (the time rate of change of momentum of the fluid particles within this stream tube slice must equal to the forces acting on it).

$$
\mathrm{F}=\text { mass } * \text { acceleration }
$$

Consider a small element of the flowing fluid as shown below, Let

dA : cross-sectional area of the fluid element,

$\mathrm{dL}$ : Length of the fluid element,

$\mathrm{dW}$ : Weight of the fluid element,

$\mathrm{u} \quad$ : Velocity of the fluid element,

$\mathrm{P} \quad$ : Pressure of the fluid element.

Assuming that the fluid is steady, non-viscous (the frictional losses are zero) and incompressible (the density of fluid is constant).

The forces on the cylindrical fluid element are,

1. Pressure force acting on the direction of flow (PdA).

2. Pressure force acting on the opposite direction of flow $[(\mathrm{P}+\mathrm{dP}) \mathrm{dA}]$.

3. A component of gravity force acting on the opposite direction of flow (dW $\sin \theta)$.

Hence, Total force $=$ gravity force + pressure force

The pressure force in the direction of low

$$
\mathrm{Fp}=\mathrm{PdA}-(\mathrm{P}+\mathrm{dP}) \mathrm{dA}=-\mathrm{dPdA}
$$


The gravity force in the direction of flow

$$
\begin{aligned}
\mathrm{Fg} & =-\mathrm{dW} \sin \theta\{\mathrm{W}=\mathrm{m} \mathrm{g}=\rho \mathrm{dAdL} \mathrm{g}\} \\
& =-\rho \mathrm{gdAdL} \sin \theta\{\sin \theta=\mathrm{dz} / \mathrm{dL}\} \\
& =-\rho \mathrm{gdAdz} .
\end{aligned}
$$

The net force in the direction of flow

$$
\begin{aligned}
& =\rho \mathrm{dAdL} \text { a. } \\
& =\rho \mathrm{dA} \mathrm{u} \mathrm{du.}
\end{aligned}
$$$$
\mathrm{F}=\mathrm{m} \text { a }\{\mathrm{m}=\rho \mathrm{dAdL}
$$

We have

$\rho \mathrm{dA} \mathrm{u} \mathrm{du}=-\mathrm{dP} d \mathrm{~A}-\rho \mathrm{g} \mathrm{dA} \mathrm{dz}\{\div \rho \mathrm{dA}\}$

$\Rightarrow \mathrm{dP} / \rho+\mathrm{udu}+\mathrm{dz} \mathrm{g}=0$--------- Euler's equation of motion.

Bernoulli's equation could be obtain by integration the Euler's equation.

$\int \mathrm{dP} / \rho+\int \mathrm{udu}+\int \mathrm{dz} \mathrm{g}=$ constant

$\Rightarrow \mathrm{P} / \rho+\mathrm{u} 2 / 2+\mathrm{z} \mathrm{g}=$ constant.

$\Rightarrow \Delta \mathrm{P} / \rho+\Delta \mathrm{u} 2 / 2+\Delta \mathrm{z} g=0$-- Bernoulli's equation.

\subsection{Kappa-Epsilon Model}

The K-epsilon model is most commonly used to describe the behavior of turbulent flows.It was proposed by A.N Kolmogrov in 1942, then modified by Harlow and Nakayama and produced K-Epsilon model for turbulence. The Transport Equations for K-Epsilon model are for $\mathrm{k}$,

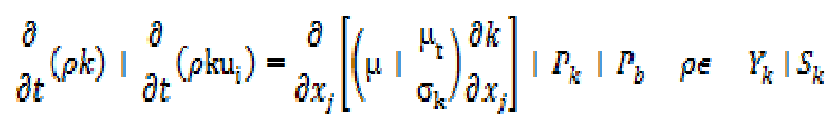

For,

$\frac{\partial}{\partial t}(\rho \epsilon)+\frac{\partial}{\partial t}\left(\rho \epsilon \mathrm{u}_{j}\right)=\frac{\partial}{\partial x_{i}}\left[\left(\mu+\frac{\mu_{z}}{\sigma_{k}}\right) \frac{\partial \epsilon}{\partial x_{j}}\right]+C_{1 \mathrm{~s}} \frac{\epsilon}{k}\left(p_{k}+C_{9 \varepsilon} P_{b}\right)-C_{2 \varepsilon} p \frac{\epsilon^{2}}{k}++5_{\varepsilon}$

Realizable k-epsilon model and RNG k-epsilon model are some other variants of K-epsilon model. K-epsilon model has solution in some special cases. K-epsilon model is only useful in regions with turbulent, high Reynolds number flows.

\section{RESULTS}

\subsection{Flow Analysis in Sudden and Gradual}

\section{Enlargement of Pipe:}

Table-5.1.1: Experimental Results of Sudden and Gradual Change of Elargement.

\begin{tabular}{|c|c|c|}
\hline Parameters & $\begin{array}{c}\text { Sudden Change } \\
\text { Valves }\end{array}$ & $\begin{array}{c}\text { Gradual Change } \\
\text { Values }\end{array}$ \\
\hline $\begin{array}{c}\text { Larger diameter } \\
\text { (outlet) }\end{array}$ & $0.040 \mathrm{~m}$ & $0.040 \mathrm{~m}$ \\
\hline $\begin{array}{c}\text { Small diameter } \\
\text { (inlet) }\end{array}$ & $0.020 \mathrm{~m}$ & $0.020 \mathrm{~m}$ \\
\hline $\begin{array}{c}\text { Length of the } \\
\text { large dia. Pipe }\end{array}$ & $0.040 \mathrm{~m}$ & $0.040 \mathrm{~m}$ \\
\hline
\end{tabular}

\begin{tabular}{|c|c|c|}
\hline $\begin{array}{c}\text { Length of the } \\
\text { small dia. Pipe }\end{array}$ & $0.060 \mathrm{~m}$ & $0.050 \mathrm{~m}$ \\
\hline Inlet velocity & $5.5 \mathrm{~m} / \mathrm{s}$ & $5.5 \mathrm{~m} / \mathrm{s}$ \\
\hline Max. velocity & $6.118093 \mathrm{~m} / \mathrm{s}$ & $6.089621 \mathrm{~m} / \mathrm{s}$ \\
\hline Min. pressure & $-4.33 \mathrm{e}^{+03}$ & $-6.39 \mathrm{e}^{+03}$ \\
\hline Max. pressure & $6.58 \mathrm{e}^{+03}$ & $1.14 \mathrm{e}^{+04}$ \\
\hline
\end{tabular}

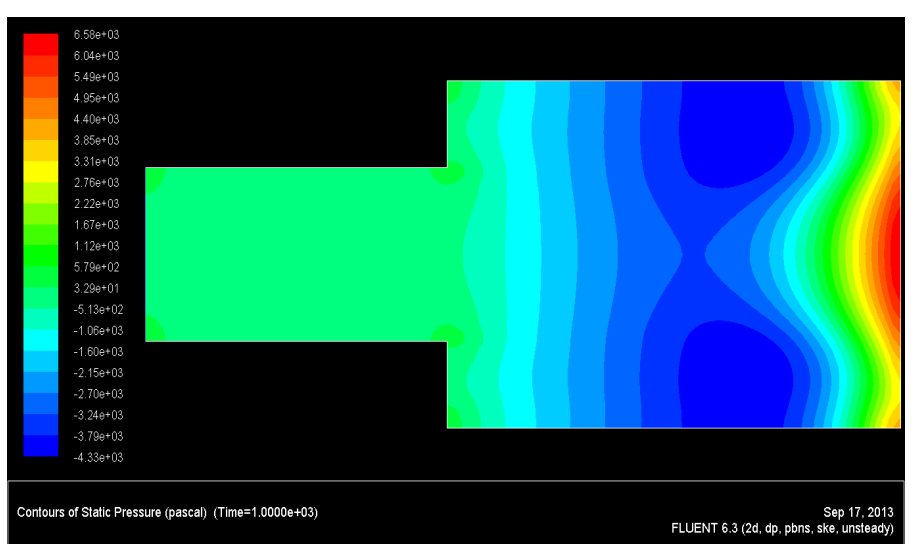

Fig-5.1.1: Pressure Contour of Sudden Enlargement

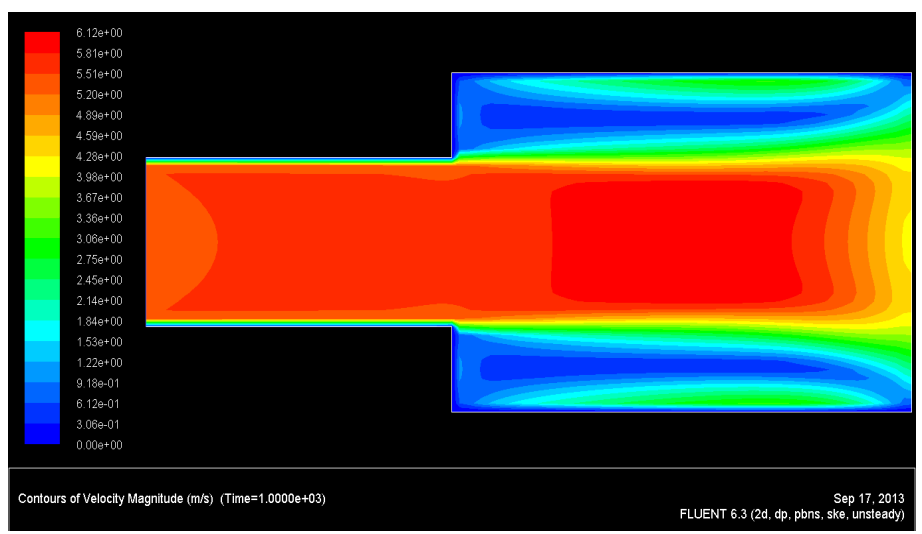

Fig-5.1.2: Velocity Contour of Sudden Enlargement.

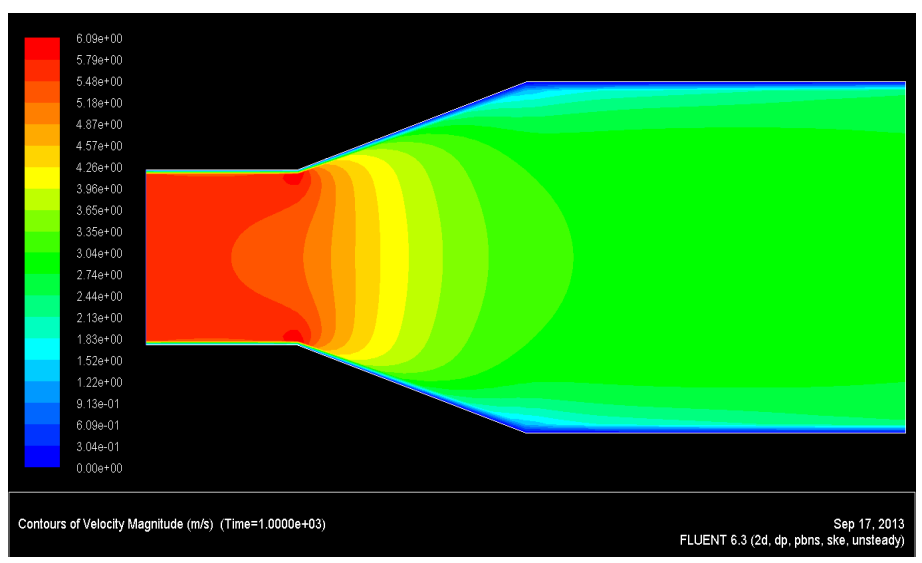

Fig-5.1.3: Velocity Contour of Gradual Enlargement. 


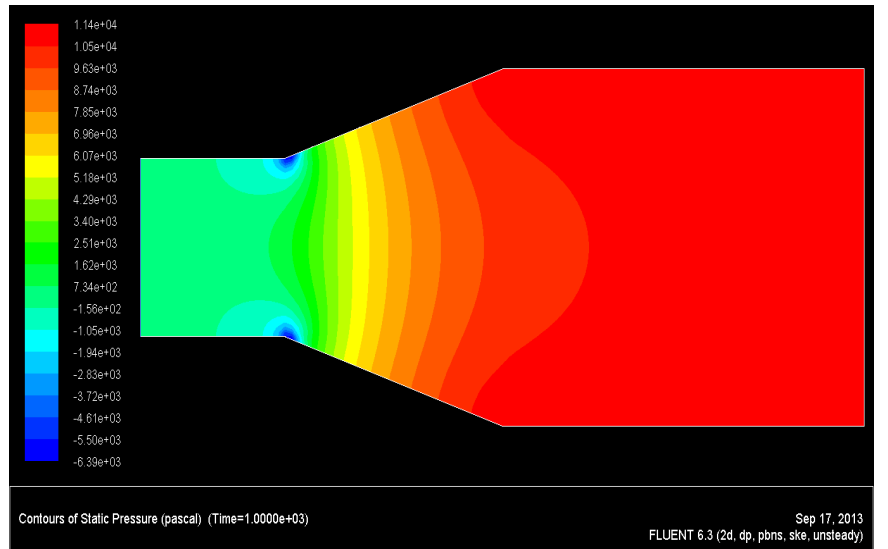

Fig-5.1.4: Pressure Contour of Gradual Enlargement.

\subsection{Flow analysis in sudden and gradual} contraction of pipe:

Table-5.2.1: Experimental Results of Sudden and Gradual Change of Contraction.

\begin{tabular}{|c|c|c|}
\hline Parameters & $\begin{array}{c}\text { Sudden contraction } \\
\text { Value }\end{array}$ & $\begin{array}{c}\text { gradual contraction } \\
\text { values }\end{array}$ \\
\hline $\begin{array}{c}\text { Large } \\
\text { diameter } \\
\text { (outlet) }\end{array}$ & $0.040 \mathrm{~m}$ & $0.040 \mathrm{~m}$ \\
\hline $\begin{array}{c}\text { Small } \\
\text { diameter } \\
\text { (inlet) }\end{array}$ & $0.020 \mathrm{~m}$ & $0.020 \mathrm{~m}$ \\
\hline $\begin{array}{c}\text { Length of } \\
\text { the large dia. } \\
\text { Pipe }\end{array}$ & $0.040 \mathrm{~m}$ & $0.040 \mathrm{~m}$ \\
\hline $\begin{array}{c}\text { Length of } \\
\text { the small } \\
\text { dia. Pipe }\end{array}$ & $0.060 \mathrm{~m}$ & $0.050 \mathrm{~m}$ \\
\hline $\begin{array}{c}\text { Inlet } \\
\text { velocity }\end{array}$ & $5.5 \mathrm{~m} / \mathrm{s}$ & $5.5 \mathrm{~m} / \mathrm{s}$ \\
\hline $\begin{array}{c}\text { Max. } \\
\text { velocity } \\
\text { pressure }\end{array}$ & $13.03537 \mathrm{~m} / \mathrm{s}$ & $12.40112 \mathrm{~m} / \mathrm{s}$ \\
\hline $\begin{array}{c}\text { Max. } \\
\text { pressure }\end{array}$ & $-1.40 \mathrm{e}^{+05}$ & $-7.42 \mathrm{e}^{+04}$ \\
\hline Min. & $2.00 \mathrm{e}^{+04}$ & \\
\hline
\end{tabular}

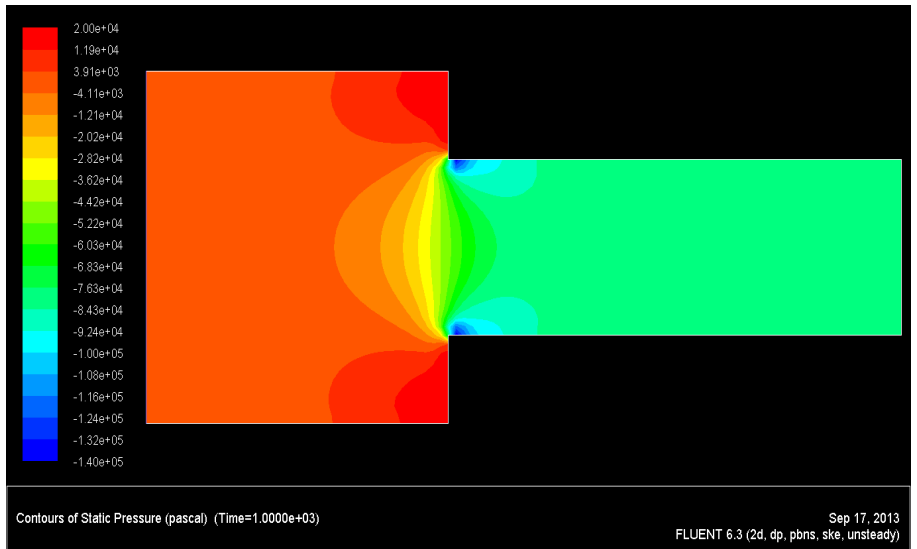

Fig-5.2.1: Pressure Contour of Sudden Contraction.

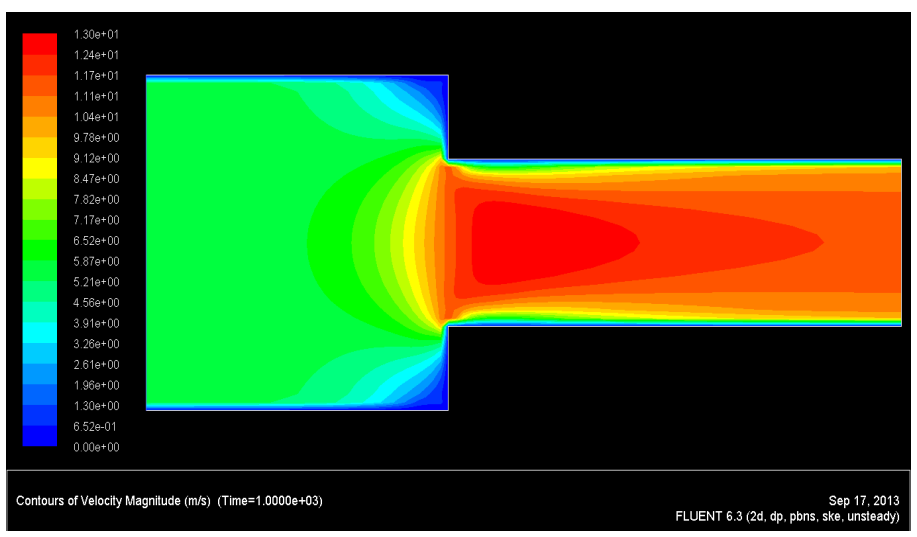

Fig-5.2.2: Velocity Contours of Sudden Contraction.

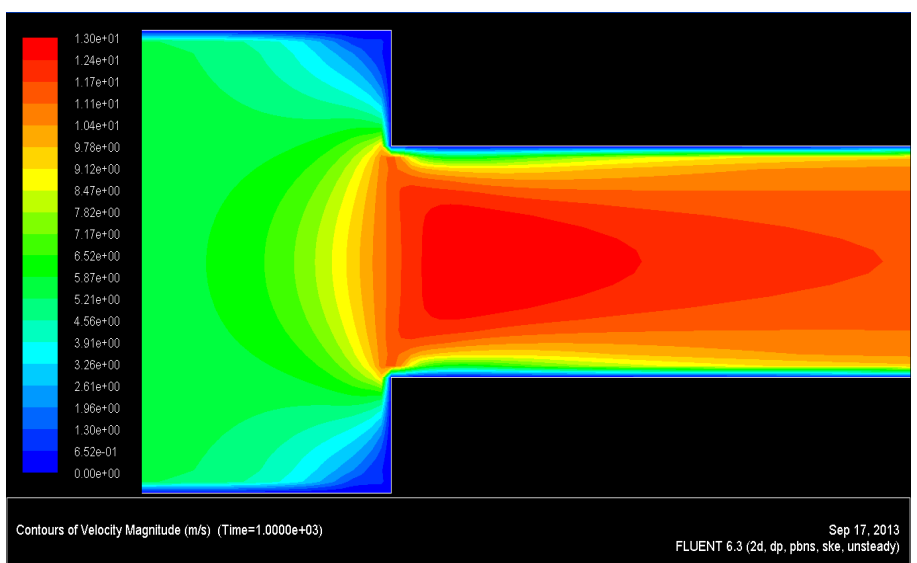

Fig-5.2.3: Venacontrata.

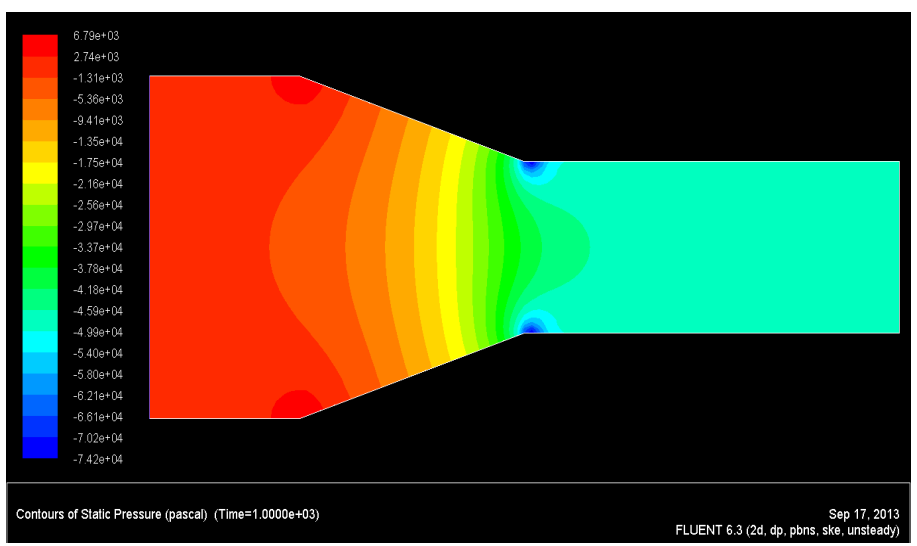

Fig-5.2.4: Pressure Contour of Gradual Contraction. 


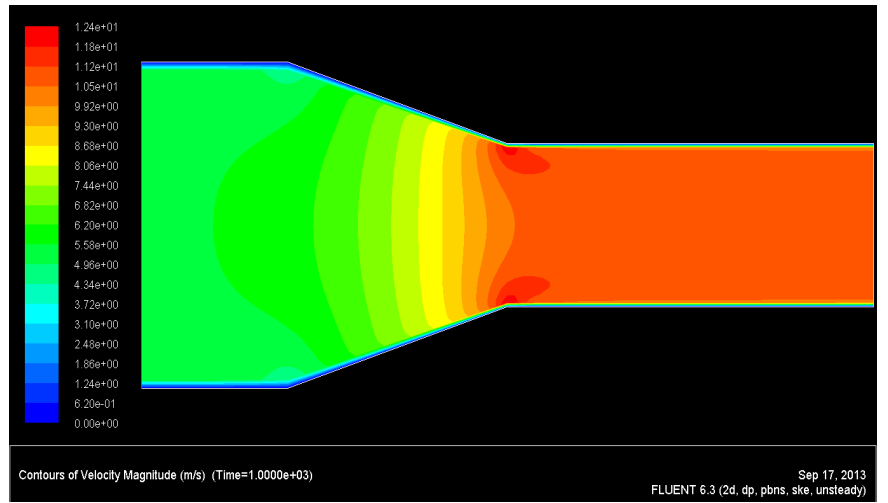

Fig-5.2.5: Velocity Contour of Gradual Contraction.

\section{CONCLUSION}

The flow through sudden and gradual change of pipe diameter(enlargement and contraction) was numerically simulated with water by unsteady flow in k-epsilon scheme. The major observations made related to the pressure and velocity contours in the process of flow through these pipes. Sudden enlargement creates more severe formation of flow eddies than sudden contraction. Also, the losses are more at the point where the enlargement in the pipe begins. In the sudden contraction, vane contracta's are formed at the point of contraction and effect of viscosity is negligible on the pressure drop through sudden contraction. The pressure drop increases with higher inlet velocity and hence with higher mass flow rate. This point is the most susceptible point for pipe damage.

So, to increase the life of the pipe in cases of sudden contraction \& enlargement, the pipes must be designed in view of the above observations making the corners more round so as to minimize the losses in the pipes.

To conclude, this examination results indicate that FLUENT can be used with high degree of accuracy to visualize the minor losses due to minor appurtenances and accessories present in a pipe network.

\section{REFERENCES}

[1] Lahiouel Y., Haddad A., Khezzar L., Chaoui K., Kondratas A.,"Development of method of routing fluid distribution networks", J. Mechanica, Vol. 43, N 4, (2003), pp. 27-34.

[2] Lahiouel Y., Haddad A., Chaoui K.,"Evaluation of head losses in fluid Transportation networks Sciences \& Technologies B - N²3, juin (2005), pp. 89-94.

[3] Weisbach J. "Die Experimental Hydraulik", Freiberg, Germany: Engelhardt, (1855).

[4] Darcy Weisbach Formula http://www.pipeflow.com/pipe-pressure-drop-calculations/ pipe-friction-loss (12/15/2011)

[5] Nikuradse J., 1933, "Strmungsgesetze in Rauben Rohren", pp 361, Verein Deutsher Ingenieure, Forschungsheft, (1933).

[6] Colebrook C.F.,"Turbulent Flow in Pipes with Particular reference to the Transition Region between the Smooth and
Rough Pipe Laws", J. Inst. of Civil Engrs.N ${ }^{\circ}$ 11,(1939), pp.133-156.

[7] Bhave, P.R.,"Analysis of flow in water distribution networks", pp.25-68 Technomic Pub. Co., Inc., USA, (1991).

[8] Rouse H., "Evaluation of Boundary Rough Proc.2nd Hydraulic. Conf., Bulletin $\mathrm{N}^{\circ}$ 27, Univ. of Lowa, Lowa City, (1943).

[9] Moody L.F., "Friction Factors for Pipe Flow", Trans. American Society of Mechanical. Engineers. No. 66, (1944), pp. 671-684.

[10] Hazen-Williams Formula http://www.pipeflow.com/pipe-pressure-drop-calculations/ pipe-friction-loss

[11]Ansys,Inc.http://http://www.idac.co.uk/products/downlo ads/ Meshing.pdf

[12] Tobias Zitzmann1, Malcolm Cook2, Peter Pfrommer1, Simon Rees2, Ljiljana Marjanovic2, "Simulation Of SteadyState Natural Convection Using CFD” Ninth International IBPSA Conference Montréal, Canada.

\section{BIOGRAPHIES:}

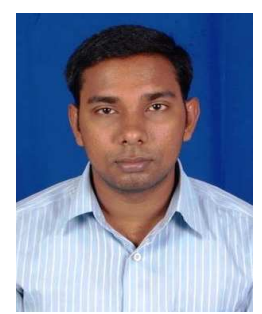

Mr. G. Satish has been working as Assistant Professor in the Department of Mechanical Engineering at Shri Vishnu Engineering College for Women, Bhimavaram and obtained his M.Tech (Machine Design) degrees with first class at JNTUK. He has experience of 2years as CAD engineer and 2years teaching and published 3 international journals.

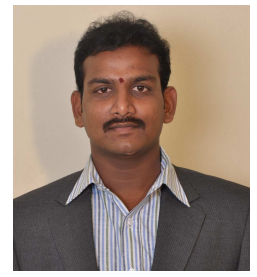

Mr.K.Ashok Kumar working as an Assistant Professor in the Department of Mechanical Engineering at Shri Vishnu Engineering College for Women, Bhimavaram. Mr. K.Ashok Kumar obtained his B.E first class at TJIT, Channai, M.Tech first class with distinction from GIET, Rajahmundry and have 1year industrial and 2 years teaching experience.

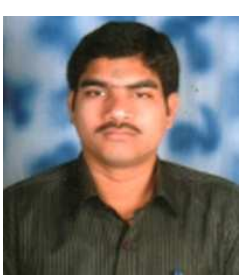

Mr.V.Vara Prasad working as an Assistant Professor in the mechanical department at shri Vishnu engineering college for women,bhimavaram.and completed M.Tech (Machine Design) with first class at Dr.paul Raj engineering college and had experience of 2 years.

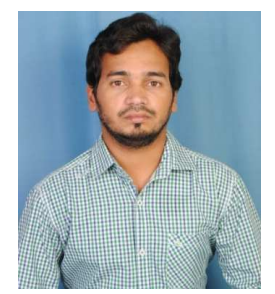

Mr.S.K.M.Pasha working as Assistant Professor in the mechanical Department at shri Vishnu engineering college for women, Bhimavaram. 